\title{
Monitoring Consumption of Common Illicit Drugs in Kuala Lumpur, Malaysia, by Wastewater-Cased Epidemiology
}

\author{
Peng Du ${ }^{1,2}{ }^{\circ}$, Xin Liu $^{3}$, Guangcai Zhong ${ }^{3}$, Zilei Zhou ${ }^{2}$, Margaret William Thomes ${ }^{4}$, \\ Choon Weng Lee ${ }^{4,5}$, Chui Wei Bong ${ }^{4,5}$, Xuan Zhang ${ }^{1}$, Fanghua Hao ${ }^{1}$, Xiqing $\mathrm{Li}^{2, *}$, \\ Gan Zhang ${ }^{3, *}$ and Phong K. Thai ${ }^{6}$ \\ 1 Beijing Key Laboratory of Urban Hydrological Cycle and Sponge City Technology, College of Water Sciences, \\ Beijing Normal University, Beijing 100875, China; dup@bnu.edu.cn (P.D.); xuan@bnu.edu.cn (X.Z.); \\ fanghua@bnu.edu.cn (F.H.) \\ 2 Laboratory of Earth Surface Processes, College of Urban and Environmental Sciences, Peking University, \\ Beijing 100871, China; zhouzilei@pku.edu.cn \\ 3 State Key Laboratory of Organic Geochemistry, Guangzhou Institute of Geochemistry, Chinese Academy of \\ Sciences, Guangzhou 510640, China; liuxin@gig.ac.cn (X.L.); gczhong@gig.ac.cn (G.Z.) \\ 4 Institute of Biological Sciences, University of Malaya, Kuala Lumpur 50603, Malaysia; \\ margaretwt@um.edu.my (M.W.T.); lee@um.edu.my (C.W.L.); cwbong@um.edu.my (C.W.B.) \\ 5 Institute of Ocean and Earth Sciences (IOES), University of Malaya, Kuala Lumpur 50603, Malaysia \\ 6 Queensland Alliance for Environmental Health Sciences (QAEHS), The University of Queensland, \\ Brisbane 4102, Queensland, Australia; p.thai@uq.edu.au \\ * Correspondence: xli@urban.pku.edu.cn (X.L.); zhanggan@gig.ac.cn (G.Z.)
}

Received: 17 December 2019; Accepted: 23 January 2020; Published: 31 January 2020

\begin{abstract}
Southeast Asian countries including Malaysia play a major role in global drug trade and abuse. Use of amphetamine-type stimulants has increased in the past decade in Malaysia. This study aimed to apply wastewater-based epidemiology for the first time in Kuala Lumpur, Malaysia, to estimate the consumption of common illicit drugs in urban population. Influent wastewater samples were collected from two wastewater treatment plants in Kuala Lumpur in the summer of 2017. Concentrations of twenty-four drug biomarkers were analyzed for estimating drug consumption. Fourteen drug residues were detected with concentrations of up to $1640 \mathrm{ng} / \mathrm{L}$. Among the monitored illicit drugs, 3,4-methylenedioxy-methamphetamine (MDMA) or ecstasy had the highest estimated per capita consumptions. Consumption and dose of amphetamine-type stimulants (methamphetamine and MDMA) were both an order of magnitude higher than those of opioids (heroin and codeine, methadone and tramadol). Amphetamine-type stimulants were the most prevalent drugs, replacing opioids in the drug market. The prevalence trend measured by wastewater-based epidemiology data reflected the shift to amphetamine-type stimulants as reported by the Association of Southeast Asian Nations Narcotics Cooperation Center. Most of the undetected drug residues were new psychoactive substances (NPSs), suggesting a low prevalence of NPSs in the drug market.
\end{abstract}

Keywords: substance abuse; MDMA; methamphetamine; ketamine; wastewater analysis; Southeast Asia

\section{Introduction}

According to the United Nations Office on Drug and Crime, both the range of drugs and drug markets are consistently expanding and diversifying more than ever before [1]. Production of opium and manufacturing of cocaine are at the highest levels ever recorded, and markets for cocaine and 
methamphetamine are extending beyond their usual regions [1]. Southeast Asian countries including Malaysia play a major role in global drug trade and abuse [2,3]. Together with trafficking activities, the use of illicit drugs causes a major problem in Southeast Asian countries, with an increasing rate of drug use in Malaysia [4]. Opioids (i.e., heroin, morphine) continue to be the main drugs of abuse in Malaysia, whereas amphetamine-type stimulants (i.e., ecstasy, methamphetamine) have been recently identified as a growing problem [5]. As a popular club drug, use of ketamine has also increased in recent years [2]. In order to formulate appropriate evidence-based public health and law enforcement policies to protect the public from adverse effects of drug abuse, it is important to have timely and accurate information about the prevalence of drug consumption in the population [6].

Over the last decade, wastewater-based epidemiology, a cost-effective approach to monitor total drug consumption in the population, has been widely applied across Europe [7-10], North America [11,12], Australia [13-15] and Asia [16-18]. After years of development, results of wastewater-based epidemiology studies have been adopted as complementary approaches for monitoring drug consumption by authorities in some countries [19]. A synchronized global wastewater-based epidemiology study can provide rapid, objective and up-to-date information to display a world map of drug use [20]. It can be especially useful in supporting drug use evaluation and in comparing different countries and regions from a global perspective. Such vision can be achieved with more wastewater-based epidemiology studies conducted in countries where traditional surveys are difficult to be done. For example, Archer et al. applied the approach to estimate drug use in South Africa as the first wastewater-based epidemiology study on the African continent [21]. Causanilles et al. reported for the first time the estimated drug consumption in Costa Rica, a tropical country of Central America [22]. Subedi et al. carried out the first wastewater-based epidemiology study in India, a South Asian country with the second largest population in the world [23].

Addressing the illicit drug problem is the top priority of Malaysian authorities [24], which requires good estimates of illicit drug consumption as a prerequisite for planning any drug control measures. However, the illicit nature of drug use and the cultural and social stigma against drug addicts in Asia have so far prevented relevant authorities to obtain good estimates of illicit drug consumption in Malaysia. Wastewater-based epidemiology could be used as a complementary monitoring approach, as it provides the total population consumption without revealing any individual information [25]. A recent report on the contemporary drug policy of the region has recommended the use of wastewater-based epidemiology to improve illicit drug demand estimates [26]. However, to the authors' knowledge, a wastewater-based epidemiology study has not yet been conducted in Malaysia.

Thus, the objective of this work was to obtain, for the first time, a snapshot of the level and profile of illicit drug use in Kuala Lumpur, the capital city of Malaysia, using a wastewater-based epidemiology approach. Wastewater samples were collected from an urban, dense residential community and analyzed for 24 drug biomarkers covering a range of common illicit drugs. Consumption of drugs was estimated and compared with data available in the literature to evaluate the drug use situation in Malaysia.

\section{Materials and Methods}

\subsection{Reagents and Materials}

Standard solutions of twenty-four target analytes and their corresponding deuterated analogs (utilized as internal standards, IS) were purchased from Cerilliant (Round Rock, TX, USA), with details listed in Table S1. The selected targets covered a range of common illicit drugs that are prevalent in Asia, including Malaysia, and most other countries around the world. Having those drugs analyzed in this study facilitated the comparison with previous studies. Formic acid and ammonium formate (HPLC grade) were obtained from CNW Technologies GmbH (Düsseldorf, Germany). HPLC-grade methanol $(\mathrm{MeOH})$ was from Fisher Scientific (Waltham, MA, USA). Hydrochloric acid (AR) and ammonium hydroxide (AR) were purchased from Beijing Chemical Works (Beijing, China). Oasis MCX 
SPE cartridges $(60 \mathrm{mg}, 3 \mathrm{~mL}$ ) were obtained from Waters Corporation (Milford, MA, USA). Ultrapure water was prepared through a Milli-Q ultrapure system (Millipore, MA, USA).

\subsection{Sample Collection}

Wastewater samples were collected from two wastewater treatment plants (WWTPs) (designated as A and B) in Kuala Lumpur, Malaysia. WWTP-A $\left(101.6706639^{\circ} \mathrm{E}, 3.102744444^{\circ} \mathrm{N}\right)$ treats an average of $50,186 \mathrm{~m}^{3}$ per day (domestic wastewater, without hospital wastewater) and serves an urban residential community with approximately 220,000 inhabitants. Seven consecutive workdays of influent wastewater samples were collected at WWTP-A in June, July and August, 2017. WWTP-B $\left(101.7403833^{\circ} \mathrm{E}, 3.102788889^{\circ} \mathrm{N}\right)$ treats an average of $308 \mathrm{~m}^{3}$ per day (hospital wastewater), serving approximately 1400 people. Six consecutive workdays of influent wastewater samples were collected at WWTP-B in July, 2017. WWTP-B serves a hospital where illicit drug consumption is not expected. Therefore, samples from WWTP-B were used as a control for comparing the profile of drug residues with WWTP-A. Samples on weekends were not collected in both WWTPs because entry was denied during this period. Twenty-four-hour time-proportional composite samples were collected through auto-samples (programmed to draw $1 \mathrm{~L}$ per hour) in each WWTP. Following collection, the composite samples were acidified to $\mathrm{pH} 2$ by $2 \mathrm{M} \mathrm{HCl}$, carried back to the laboratory, and stored at $-20{ }^{\circ} \mathrm{C}$ until analysis.

\subsection{Analysis}

Sample pretreatment and analysis followed the procedure described in previous publications $[27,28]$ with minor modifications. First, $50 \mathrm{~mL}$ wastewater was filtered through a glass fiber membrane to remove solid particles, then spiked with deuterated IS $(100 \mu \mathrm{L}, 200 \mu \mathrm{g} / \mathrm{L})$ before SPE extraction. An Oasis MCX cartridge was conditioned in sequence with $6 \mathrm{~mL} \mathrm{MeOH}, 4$ $\mathrm{mL}$ ultrapure water $(\mathrm{pH}=7)$ and another $4 \mathrm{~mL}$ ultrapure water $(\mathrm{pH}=2)$ at a rate of $1-2 \mathrm{~mL} / \mathrm{min}$. The sample was loaded to the conditioned Oasis MCX cartridge under vacuum at the same flow rate. Following loading, the cartridge was washed in sequence with $2 \mathrm{~mL}$ ultrapure water $(\mathrm{pH}=2)$ and $2 \mathrm{~mL} \mathrm{MeOH}$ under vacuum. The cartridge was dried under vacuum, and it was eluted with $4 \mathrm{~mL}$ $\mathrm{MeOH}$ and $4 \mathrm{~mL}$ of $5 \% \mathrm{NH}_{3}$ in $\mathrm{MeOH}$. The eluate was evaporated until dry by a gentle $\mathrm{N}_{2}$ stream, then reconstituted in $400 \mu \mathrm{L} \mathrm{MeOH} /$ ultrapure water $(1 / 5, \mathrm{v} / \mathrm{v})$. The final extract was filtered through a $0.2 \mu \mathrm{m}$ modified nylon centrifugal filter (VWR International, Radnor, PA, USA) before analysis.

Target analytes were separated using an ultra-fast liquid chromatography (UFLC) system (20 AD-XR, Shimadzu, Japan) with a Phenomenex Gemini C18 column $(100 \times 2 \mathrm{~mm}, 3 \mu \mathrm{m})$. The mobile phase was composed of $30 \mathrm{mM}$ ammonium formate in ultrapure water, with $\mathrm{pH}$ adjusted to 3.5 by formic acid (A) and $\mathrm{MeOH}(\mathrm{B})$. The elution gradient was as follows: $0-0.1 \mathrm{~min}, 5 \% \mathrm{~B} ; 0.1-3.0 \mathrm{~min}, 30 \%$ B; 3.0-5.0 min, 80\% B; 5.0-5.5 min, 95\% B; 5.5-9.5 min, 95\% B; 9.5-9.6 min, 5\% B; 9.6-14.0 min, 5\% B (Figure S1). The injection volume was $5 \mu \mathrm{L}$, and the flow rate of the mobile phase was controlled at $0.3 \mathrm{~mL} / \mathrm{min}$. Concentrations were determined using an API-4000 triple quadrupole mass spectrometer (AB SCIEX, Boston, MA, USA) equipped with an electrospray interface operating in positive ionization mode. The quantification of the mass spectrometry (MS) system was operated in multiple reaction monitoring (MRM) mode. Details of MS parameters (declustering potential, collision energy, quantifier and qualifier ions), IS and retention time are described in Table S2.

The analytical procedures were subjected to strict quality control and quality assurance measures. The limit of detection (LOD), limit of quantification (LOQ), recoveries, matrix effects, repeatability and reproducibility were examined according to previously established protocol [29]. The recoveries and matrix effects of target compounds ranged from $83.6 \% \pm 10.1 \%$ to $104.9 \% \pm 6.2 \%$ and from $-10.1 \% \pm$ $6.6 \%$ to $17.2 \% \pm 7.3 \%$, respectively. Procedure blanks using ultrapure water $(\mathrm{pH}=2)$ spiked with IS were included in every 10th sample for checking the potential interference and contamination, and all target analytes were below LOD in blanks. More details can be found in the Supplementary Materials (Table S3). 


\subsection{Mass Load and Consumption Calculation}

The daily mass load of each drug residue per 1000 inhabitants at a specific WWTP was estimated by Equation (1). $C_{i}$ is the influent concentration of the target drug residue, $F_{I n}$ is the influent flow rate of the specific WWTP and PS is the population served by the WWTP.

$$
\begin{aligned}
\text { Load }(m g / 1000 \mathrm{inh} / d) & =\frac{C_{i}(n g / L) \times F_{I n}(L / d)}{\frac{P S}{1000}} \times \frac{1}{10^{6}}\left(\frac{m g}{n g}\right) \\
\text { Consumption } & =\text { Load } \times \frac{M W_{p i}}{M W_{m i}} \times \frac{1}{E F_{i}}
\end{aligned}
$$

The consumption (mg/1000 inh/d) of target drug was estimated by Equation (2), where $E F_{i}$ is excretion factor of a given dose of target drug excreted as unchanged parent or metabolite through urine, $M W_{p i}$ is the molecular weight of the parent, and $M W_{m i}$ is the molecular weight of the metabolite. The human excretion factors of the target drug are shown in Table S4. Uncertainties involved in the above estimation process have been discussed in previous studies [30,31].

\subsection{Statistical Analysis}

Statistical analysis was performed via SPSS 20 (IBM Co., Armonk, NY, USA), and the difference was statistically significant with a $p$-value below 0.05. The Kolmogorov-Smirnov (K-S) test was employed for a normal test before other analyses. Pearson correlation analysis was used to assess the correlation between loads of the unchanged parent and metabolite. Student's $t$-test was used to compare the differences of mass loads between WWTP-A and -B.

\section{Results and Discussion}

\subsection{Occurrence and Daily Mass Loads of Drug Residues in Influents}

Fourteen among 24 target drug biomarkers were detected in the influent samples of WWTP-A, with the concentrations ranging from $<\mathrm{LOD}$ (6-acetylmorphine and 3,4-methylene-dioxyamphetamine (MDA)) to $1640 \mathrm{ng} / \mathrm{L}$ (methamphetamine) (Table 1). Methamphetamine had the highest mean concentration $(1014 \pm 246 \mathrm{ng} / \mathrm{L})$, followed by 3,4-methylenedioxymethamphetamine (MDMA) (812 \pm $346 \mathrm{ng} / \mathrm{L})$, ketamine $(274 \pm 39 \mathrm{ng} / \mathrm{L})$ and tramadol $(185 \pm 30 \mathrm{ng} / \mathrm{L})$. The mean concentrations of other drug residues were all below $100 \mathrm{ng} / \mathrm{L}$. In the small WWTP-B, only eleven drug residues were detected, with the mean concentrations ranging from $6 \pm 9 \mathrm{ng} / \mathrm{L}$ (morphine) to $639 \pm 95 \mathrm{ng} / \mathrm{L}$ (tramadol) (Table 1).

A strong, positive correlation $(p<0.001)$ was found between influent amphetamine and methamphetamine concentrations in WWTP-A, and the mean ratio was $0.068 \pm 0.016$. These low ratios $(<0.1)$ indicated that amphetamine detected in the samples mainly came from methamphetamine use, not from amphetamine use itself [32,33]. Positive correlations $(p<0.05)$ were also found between cocaine and benzoylecgonine, 2-ethylidene-1,5-dimethyl-3,3-diphenylpyrrolidine (EDDP) and methadone, and ketamine and norketamine; the mean ratios were $0.35 \pm 0.19,3.60 \pm 1.12$ and $3.03 \pm 0.43$, which was consistent with previous reports in wastewater [34]. This suggested that the drug residues measured in our samples were primarily from human consumption rather than from random dumping. Emerging illicit drugs such as cathinone, p-methoxymethamphetamine, methylone, mephedrone, 4-iodo-2,5-dimethoxyphenethylamine, 3,4-methylenedioxypyrovalerone, benzylpiperazine, 3-trifluoromethylphenylpiperazine, 1-(3-chloro-phenyl) piperazine and low-dose fentanyl were not detected. The results indicated that the use of these new psychoactive substances was not as prevalent as the other common illicit drugs in the studied area.

In WWTP-A, methamphetamine, MDMA, ketamine and tramadol had higher mean mass loads than other drugs, with the values of $231 \pm 56 \mathrm{mg} / 1000 \mathrm{inh} / \mathrm{d}, 185 \pm 79 \mathrm{mg} / 1000 \mathrm{inh} / \mathrm{d}, 62 \pm 9 \mathrm{mg} / 1000 \mathrm{inh} / \mathrm{d}$ and $42 \pm 7 \mathrm{mg} / 1000 \mathrm{inh} / \mathrm{d}$, respectively (Table 2). For WWTP-B, tramadol had the highest influent mean load (144 \pm 21$)$, followed by ketamine $(62 \pm 5 \mathrm{mg} / 1000 \mathrm{inh} / \mathrm{d})$ and methamphetamine $(30 \pm$ 
$16 \mathrm{mg} / 1000 \mathrm{inh} / \mathrm{d}$ ) (Table 2). The profile of drug residues in WWTP-A was different from that in WWTP-B, which was attributed to different sources of influents from WWTP-A (domestic wastewater) and WWTP-B (wastewater from a hospital). It was reasonable that the loads of the pain-killer tramadol were much higher in samples from WWTP-B, while the loads of illicit drugs were higher in WWTP-A $(p<0.05)$.

Table 1. Statistics of drug residue concentrations (ng/L) in wastewater treatment plant (WWTP)-A and $-\mathrm{B}$.

\begin{tabular}{|c|c|c|c|c|c|c|c|c|}
\hline \multirow{2}{*}{ Drug Residues } & \multicolumn{4}{|c|}{ WWTP-A $(n=20)$} & \multicolumn{4}{|c|}{ WWTP-B $(n=6)$} \\
\hline & $\mathrm{DF}^{\mathrm{a}}(\%)$ & Range & Mean \pm STD $^{b}$ & Median & DF (\%) & Range & Mean \pm STD & Median \\
\hline Methamphetamine & 100 & $690-1640$ & $1014 \pm 246$ & 956 & 100 & $47-225$ & $132 \pm 72$ & 118 \\
\hline Ketamine & 100 & $188-354$ & $274 \pm 39$ & 284 & 100 & $243-311$ & $276 \pm 24$ & 279 \\
\hline Norketamine & 100 & $51-106$ & $91 \pm 14$ & 94 & 100 & $146-206$ & $175 \pm 20$ & 174 \\
\hline Morphine & 100 & $35-93$ & $65 \pm 14$ & 67 & 33 & $<$ LOD -22 & $6 \pm 9$ & $<\mathrm{LOD}$ \\
\hline 6-acetylmorphine & 20 & $<$ LOD-13 & $2 \pm 4$ & $<\mathrm{LOD}$ & 0 & $<\mathrm{LOD}$ & $<\mathrm{LOD}$ & $<\mathrm{LOD}$ \\
\hline Cocaine & 100 & $1-11$ & $6 \pm 3$ & 5 & 0 & $<\mathrm{LOD}$ & $<\mathrm{LOD}$ & $<\mathrm{LOD}$ \\
\hline Benzoylecgonine & 100 & $6-35$ & $19 \pm 8$ & 16 & 0 & $<\mathrm{LOD}$ & $<\mathrm{LOD}$ & $<\mathrm{LOD}$ \\
\hline MDMA & 100 & 290-1296 & $812 \pm 346$ & 936 & 100 & $5-52$ & $54 \pm 59$ & 28 \\
\hline MDA & 95 & $<$ LOD-51 & $28 \pm 10$ & 29 & 100 & $<$ LOQ-91 & $53 \pm 29$ & 60 \\
\hline Methadone & 100 & $<\mathrm{LOQ}-31$ & $10 \pm 7$ & 10 & 100 & $<\mathrm{LOQ}-13$ & $8 \pm 4$ & 8 \\
\hline
\end{tabular}

Table 2. Mean influent loads (mg/1000 inh/d) of drug residues in WWTP-A and -B.

\begin{tabular}{ccccc}
\hline \multirow{2}{*}{ Drug Residues } & \multicolumn{3}{c}{ WWTP-A } & WWTP-B \\
\cline { 2 - 5 } & June & July & August & July \\
\hline Methamphetamine & $207 \pm 38$ & $201 \pm 27$ & $295 \pm 48$ & $30 \pm 16$ \\
Amphetamine & $15 \pm 3$ & $14 \pm 3$ & $19 \pm 2$ & $2 \pm 2$ \\
Ketamine & $57 \pm 10$ & $62 \pm 6$ & $69 \pm 6$ & $62 \pm 5$ \\
Norketamine & $19 \pm 3$ & $21 \pm 3$ & $23 \pm 1$ & $39 \pm 5$ \\
Morphine & $17 \pm 4$ & $12 \pm 3$ & $16 \pm 2$ & $1 \pm 2$ \\
Codeine & $8 \pm 2$ & $7 \pm 2$ & $7 \pm 1$ & $2 \pm 3$ \\
6-acetylmorphine & $<1$ & $<1$ & $1 \pm 1$ & $<1$ \\
Cocaine & $1 \pm 1$ & $1 \pm 1$ & $2 \pm 1$ & $<1$ \\
Benzoylecgonine & $4 \pm 12$ & $3 \pm 2$ & $5 \pm 2$ & $<1$ \\
MDMA & $195 \pm 73$ & $145 \pm 97$ & $221 \pm 46$ & $12 \pm 13$ \\
MDA & $6 \pm 3$ & $7 \pm 2$ & $6 \pm 1$ & $12 \pm 7$ \\
Methadone & $2 \pm 1$ & $2 \pm 2$ & $2 \pm 1$ & $2 \pm 1$ \\
EDDP & $7 \pm 3$ & $7 \pm 4$ & $7 \pm 5$ & $5 \pm 1$ \\
Tramadol & $44 \pm 9$ & $40 \pm 5$ & $44 \pm 6$ & $144 \pm 21$ \\
\hline
\end{tabular}

\subsection{Estimation of Community Drug Consumption}

For the discussion of illicit drug consumption in the community, only data from WWTP-A were used, as they are representative of a large population of Kuala Lumpur where people could have easier access to drug and locations for drug use than inside the hospital served by WWTP-B.

Our monitoring study estimated the consumption of common illicit drugs such as MDMA, methamphetamine, ketamine, cocaine, heroin as well as prescribed drugs prone to abuse such as codeine, tramadol and methadone. As shown in Table 3, MDMA, methamphetamine and ketamine were the three most popular illicit drugs consumed in this population. This finding was in agreement with the recent report in which methamphetamine, MDMA and ketamine were listed as synthetic drugs of concern in the region [26]. 
Table 3. Estimated community consumption (mg/1000 inh/d) and mean dose (dose/1000 inh/d) of drugs serviced by WWTP-A.

\begin{tabular}{cccc}
\hline Drugs & June & July & August \\
\hline MDMA & $748 \pm 282^{\mathrm{a}(7.5) \mathrm{b}}$ & $558 \pm 373(5.6)$ & $850 \pm 177(8.5)$ \\
Methamphetamine & $481 \pm 88(16.0)$ & $468 \pm 64(15.6)$ & $687 \pm 112(22.9)$ \\
Ketamine & $357 \pm 64(4.8)$ & $387 \pm 35(5.2)$ & $434 \pm 40(5.8)$ \\
Cocaine & $14 \pm 6(0.1)$ & $9 \pm 4(0.1)$ & $12 \pm 4(0.1)$ \\
Tramadol & $150 \pm 32(3.0)$ & $137 \pm 17(2.7)$ & $152 \pm 21(5.1)$ \\
Methadone & $14 \pm 7(0.6)$ & $15 \pm 9(0.6)$ & $15 \pm 9(0.6)$ \\
Codeine & $26 \pm 8(0.7)$ & $22 \pm 6(0.6)$ & $24 \pm 5(0.6)$ \\
Heroin ${ }^{c}$ & $51 \pm 11(3.4)$ & $38 \pm 8(2.5)$ & $48 \pm 5(3.2)$
\end{tabular}

a Consumption (Mean \pm STD); ${ }^{b}$ Mean dose; ${ }^{\mathrm{c}}$ Assumed the morphine in influents was all coming from heroin abuse.

In this study, MDMA had the highest estimated per capita consumption, ranging from $558 \pm$ $373 \mathrm{mg} / 1000 \mathrm{inh} / \mathrm{d}$ (July) to $850 \pm 177 \mathrm{mg} / 1000 \mathrm{inh} / \mathrm{d}$ (August) in WWTP-A (Table 3). The mean MDMA consumption in this study was much higher than those reported in other countries (Figure 1). It was noteworthy that the MDMA consumption estimated in Kuala Lumpur, Malaysia, was even higher than the Netherlands, the country with the highest MDMA consumption in the latest Sewage Analysis CORe group Europe study, which reported the temporal and spatial consumption trend of common illicit drugs, including MDMA, in $>60$ cities around the world [35]. This result suggested that Malaysia is not only a substantial point of entry for MDMA to the regional market [26] but also a large consumer of this drug.

The drug with second highest consumption in Kuala Lumpur was methamphetamine with mean consumption ranging from $468 \pm 64 \mathrm{mg} / 1000 \mathrm{inh} / \mathrm{d}$ (July) to $687 \pm 112 \mathrm{mg} / 1000 \mathrm{inh} / \mathrm{d}$ (August) (Table 3). Consumption of ketamine, a popular drug of abuse in Southeast Asia [21], was also relatively high after methamphetamine, ranging from $357 \pm 64 \mathrm{mg} / 1000 \mathrm{inh} / \mathrm{d}$ (June) to $434 \pm 40 \mathrm{mg} / 1000 \mathrm{inh} / \mathrm{d}$ (August) (Table 3). Consumption of methamphetamine and ketamine measured by wastewater-based epidemiology in Kuala Lumpur was also higher than in most cities around the world (Figure 1). These results indicated that synthetic drugs were highly prevalent in the city. It could be explained by the fact that Kuala Lumpur is located in one of the most important trafficking routes of synthetic drugs in Southeast Asia [21,22]. In general, the profile of illicit drug consumption of Kuala Lumpur was different to that of other cities around the world. For example, although the levels of methamphetamine consumptions were similar between this study and two cities in South Africa [18], the prevalence of MDMA was significantly higher in Kuala Lumpur, while cocaine consumption was popular in the South African cities (Figure 1). 

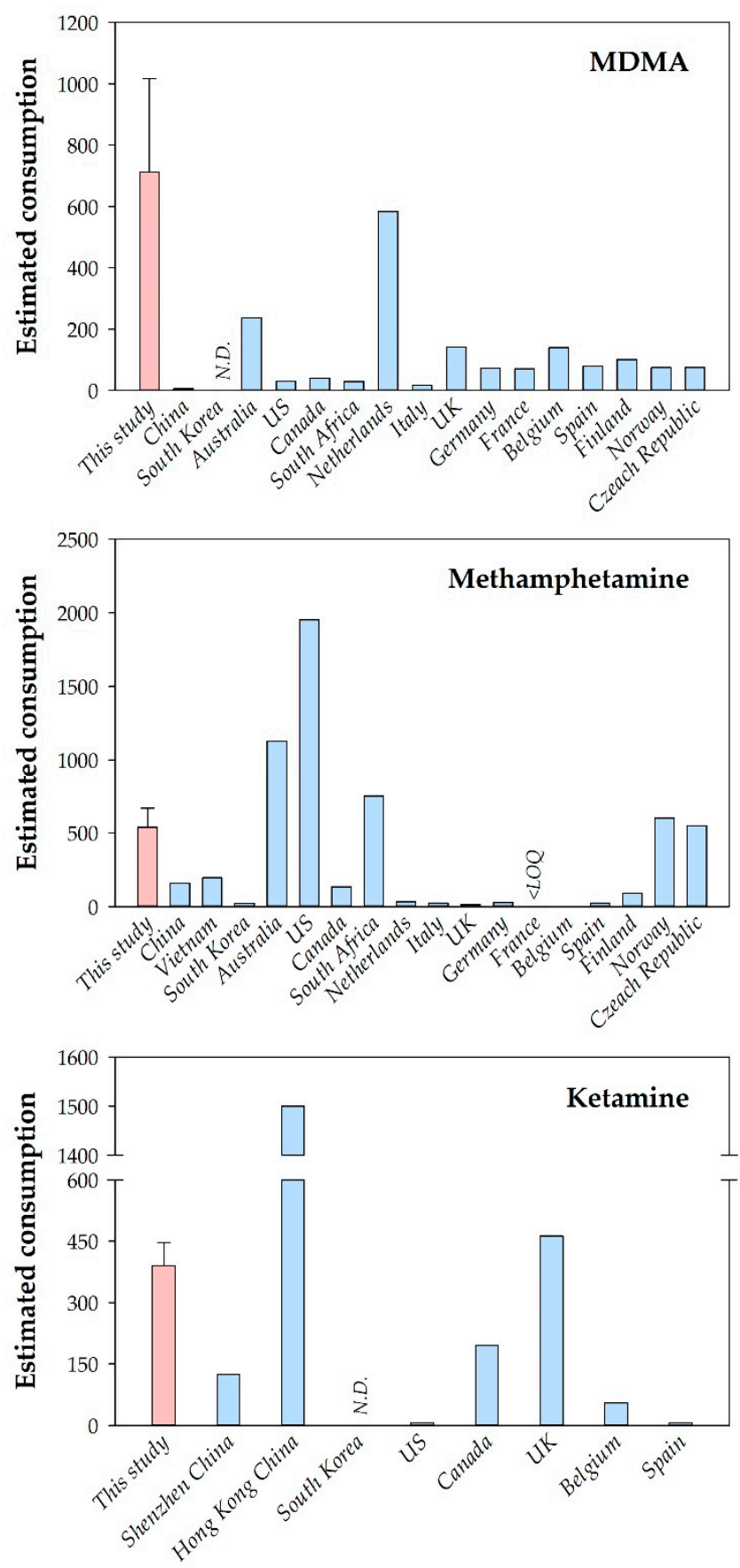

Figure 1. Estimated methamphetamine, MDMA and ketamine consumptions (mg/1000 inh/d) in this study and other countries [3,12,35-46].

Heroin and codeine are two traditional opiates. Consumption of codeine ranged from $22 \pm$ $6 \mathrm{mg} / 1000 \mathrm{inh} / \mathrm{d}$ (July) to $26 \pm 8 \mathrm{mg} / 1000 \mathrm{inh} / \mathrm{d}$ (June). It can be metabolized into morphine by the human body. In this study, the influent codeine loads were around $7 \mathrm{mg} / 1000 \mathrm{inh} / \mathrm{d}$, and the mean load of morphine from codeine metabolized was about $1 \mathrm{mg} / 1000 \mathrm{inh} / \mathrm{d}$ (based on the excretion rates of $50 \%$ and $9 \%$ ) [47]. Thus, we assumed the morphine measured in the influent samples was from heroin consumption because the morphine from actual codeine consumption was within the range of measurement error of morphine loads. Meanwhile, morphine was not mentioned as a substance of abuse in any reports about illicit drugs in Malaysia. This assumption will get an overestimated value, but it is acceptable within the allowable range of error. Hence, the estimated heroin consumption 
was in the range from $38 \pm 8 \mathrm{mg} / 1000 \mathrm{inh} / \mathrm{d}$ to $51 \pm 11 \mathrm{mg} / 1000 \mathrm{inh} / \mathrm{d}$, respectively. Consumption of methadone and tramadol ranged from $14 \pm 7 \mathrm{mg} / 1000 \mathrm{inh} / \mathrm{d}$ to $152 \pm 21 \mathrm{mg} / 1000 \mathrm{inh} / \mathrm{d}$ (Table 3).

For cocaine, the wastewater-based epidemiology-estimated consumption ranged from $9 \pm$ $4 \mathrm{mg} / 1000 \mathrm{inh} / \mathrm{d}$ to $14 \pm 6 \mathrm{mg} / 1000 \mathrm{inh} / \mathrm{d}$. Obviously, it was not as prevalent as the mentioned drugs in Kuala Lumpur, and the low consumption was consistent with the low levels of seizures cocaine in Malaysia [48].

In 2017, traditional surveys showed that the prevalence of drug abuse in Malaysia has been shifting from opiates to amphetamine-type stimulants [24]. The number of users of methamphetamine and MDMA have substantially increased while that of opiate users has decreased, especially heroin users (Table S5) [24]. Furthermore, recent data of amphetamine-type stimulants showed seizures were two orders of magnitude higher than that of opiates and synthetic opioids in recent years [23,48]. However, the survey and seizure data showed indirect and delayed information of drug use rather than the actual drug consumption [49]. Wastewater-based epidemiology estimated that amphetamine-type stimulant (methamphetamine and MDMA) consumption and doses were both an order of magnitude higher than those of opioids (heroin and codeine, methadone and tramadol), even if the consumption of heroin was overestimated (Table 3). The wastewater-based epidemiology-estimated profile of drug use reflected the changing profile of drug use and trafficking recorded by the traditional methodologies in Malaysia. This result implied that wastewater-based epidemiology could assess the prevalence and consumption of drug use more specifically, objectively and in real-time, which in turn indicated a good response of wastewater-based epidemiology to the change of profile of drug use compared to traditional monitoring approaches.

\subsection{Limitations}

The limitations of the back-estimation process by wastewater-based epidemiology have been discussed in detail elsewhere [30,50,51]. Most notably, wastewater-based epidemiology cannot provide information on prevalence and frequency of use, characteristics and types of consumers as well as the purity of drugs. Illegal synthesis processes used for the manufacturing of these drugs or dumping can also overestimate the final estimates if the parent compounds are used as biomarkers for back-estimation.

Because of the limited numbers of samples and WWTPs, the findings in this study can be considered as preliminary for the urban area of Kuala Lumpur. Further research in the field should be conducted to get spatial-temporal variations and involve more communities in Southeast Asian countries for longer sampling periods.

\section{Conclusions}

Using wastewater-based epidemiology, this study provides the first objective snapshot of local drug use in a population of Kuala Lumpur, Malaysia. Fourteen drug residues were detected with concentrations of up to $1640 \mathrm{ng} / \mathrm{L}$ in influents. MDMA had the highest estimated per capita consumption, and it was higher than most other countries around the world. The amphetamine-type stimulants (methamphetamine and MDMA) were the most prevalent drugs, replacing opioids in the drug market. The prevalence trend measured by wastewater-based epidemiology data reflected the shift to amphetamine-type stimulants, as reported by the traditional survey data in Malaysia. This study can guide and promote future wastewater-based epidemiology monitoring in Southeast Asia, and it can provide additional understanding of the drug market for the authorities.

Supplementary Materials: The following are available online at http://www.mdpi.com/1660-4601/17/3/889/s1, Table S1: Target analytes and corresponding internal standers, Table S2: MS parameters (quantifier and qualifier ions), declustering potential, collision energy and retention time, Table S3: Method validation parameters: recovery, matrix effect, reproducibility, reproducibility, LOD, LOQ and procedure bank, Table S4: The human excretion factors of the target drugs, molecular weight ratio of parent and metabolite and typical dose, Table S5: Number of drug dependents of amphetamine-type stimulants and opiates in Malaysia from 2013-2017, Figure S1: The 
elution gradient of mobile phase B (MeOH), Figure S2: Chromatogram of 24 analyzed substances and their corresponding deuterated.

Author Contributions: P.D., P.K.T., X.L. and G.Z. conceived the study. X.L., G.Z., Z.Z., M.W.T., C.W.L. and C.W.B. conducted the sampling campaign and analysis. P.D. performed the data analysis and generated the figures and tables. P.D., P.K.T., X.L., G.Z., X.L., C.W.L., C.W.B., X.Z. and F.H. wrote and reviewed the manuscript. All authors have read and agreed to the published version of the manuscript.

Funding: This research was funded by the National Natural Science Foundation of China (Grant No. 41701543 and 41877508), the Fundamental Research Funds for the Central Universities (Grant No. 2018NTST20 and 2017XTCX02), the 111 Project (B18006), the International Partnership Program of Chinese Academy of Sciences (Grant No. 132744KYSB20170002), and Institution Centre of Excellence (HiCOE) Phase II Fund, Ministry of Higher Education (IOES-2014D) Malaysia.

Acknowledgments: The authors are extremely thankful to all the personnel at the sampled wastewater treatment plants for their assistance in wastewater sampling.

Conflicts of Interest: The authors declare no conflict of interest.

\section{References}

1. UNODC (United Nations Office on Drugs and Crime). World Drug Report 2018, Executive Summary Conclusions and Policy Implications; United Nations Office on Drugs and Crime: Vienna, Austria, 2018.

2. UNODC (United Nations Office on Drugs and Crime). Synthetic Drugs in East and South-East Asia-Trends and Patterns of Amphetamine-Type Stimulants and New Psychoactive Substances; United Nations Office on Drugs and Crime: Vienna, Austria, 2019.

3. UNODC (United Nations Office on Drugs and Crime). Transnational Organized Crime in Southeast Asia: Evolution, Growth and Impact; United Nations Office on Drugs and Crime: Vienna, Austria, 2019.

4. UNODC (United Nations Office on Drugs and Crime). World Drug Report 2017; United Nations Office on Drugs and Crime: Vienna, Austria, 2017.

5. Singh, D.; Chawarski, M.C.; Schottenfeld, R.; Vicknasingama, B. Substance abuse and the HIV situation in Malaysia. J. Food Drug Anal. 2013, 21, S46-S51. [CrossRef] [PubMed]

6. Bruno, R.; Edirisinghe, M.; Hall, W.; Mueller, J.F.; Lai, F.Y.; O’Brien, J.W.; Thai, P.K. Association between purity of drug seizures and illicit drug loads measured in wastewater in a South East Queensland catchment over a six year period. Sci. Total Environ. 2018, 635, 779-783. [CrossRef] [PubMed]

7. Thomas, K.V.; Bijlsma, L.; Castiglioni, S.; Covaci, A.; Emke, E.; Grabic, R.; Hernandez, F.; Karolak, S.; Kasprzyk-Hordern, B.; Lindberg, R.H.; et al. Comparing illicit drug use in 19 European cities through sewage analysis. Sci. Total Environ. 2012, 432, 432-439. [CrossRef] [PubMed]

8. Ort, C.; van Nuijs, A.L.N.; Berset, J.D.; Bijlsma, L.; Castiglioni, S.; Covaci, A.; de Voogt, P.; Emke, E.; Fatta-Kassinos, D.; Griffiths, P.; et al. Spatial differences and temporal changes in illicit drug use in Europe quantified by wastewater analysis. Addiction 2014, 109, 1338-1352. [CrossRef] [PubMed]

9. Castrignanò, E.; Yang, Z.; Bade, R.; Baz-Lomba, J.A.; Castiglioni, S.; Causanilles, A.; Covaci, A.; Gracia-Lor, E.; Hernandez, F.; Kinyua, J.; et al. Enantiomeric profiling of chiral illicit drugs in a pan-European study. Water Res. 2018, 130, 151-160. [CrossRef]

10. Gonzalez-Marino, I.; Baz-Lomba, J.A.; Alygizakis, N.A.; Andres-Costa, M.J.; Bade, R.; Barron, L.P.; Been, F.; Berset, J.D.; Bijlsma, L.; Bodik, I.; et al. Spatio-temporal assessment of illicit drug use at large scale: Evidence from 7 years of international wastewater monitoring. Addiction 2019, 115, 109-120. [CrossRef]

11. Yargeau, V.; Taylor, B.; Li, H.; Rodayan, A.; Metcalfe, C.D. Analysis of drugs of abuse in wastewater from two Canadian cities. Sci. Total Environ. 2014, 487, 722-730. [CrossRef]

12. Subedi, B.; Kannan, K. Mass loading and removal of select illicit drugs in two wastewater treatment plants in New York State and estimation of illicit drug usage in communities through wastewater analysis. Environ. Sci. Technol. 2014, 48, 6661-6670. [CrossRef]

13. Lai, F.Y.; O’Brien, J.W.; Thai, P.K.; Hall, W.; Chan, G.; Bruno, R.; Ort, C.; Prichard, J.; Carter, S.; Anuj, S.; et al. Cocaine, MDMA and methamphetamine residues in wastewater: Consumption trends (2009-2015) in South East Queensland, Australia. Sci. Total Environ. 2016, 568, 803-809. [CrossRef]

14. Thai, P.K.; O’Brien, J.W.; Tscharke, B.J.; Mueller, J.F. Analyzing Wastewater Samples Collected during Census To Determine the Correction Factors of Drugs for Wastewater-Based Epidemiology: The Case of Codeine and Methadone. Environ. Sci. Techol. Lett. 2019, 6, 265-269. [CrossRef] 
15. O’Brien, J.W.; Grant, S.; Banks, A.P.W.; Bruno, R.; Carter, S.; Choi, P.M.; Covaci, A.; Crosbie, N.D.; Gartner, C.; Hall, W.; et al. A National Wastewater Monitoring Program for a better understanding of public health: A case study using the Australian Census. Environ. Int. 2019, 122, 400-411. [CrossRef] [PubMed]

16. Nguyen, H.T.; Thai, P.K.; Kaserzon, S.L.; O’Briena, J.W.; Eaglesham, G.; Mueller, J.F. Assessment of drugs and personal care products biomarkers in the influent and effluent of two wastewater treatment plants in Ho Chi Minh City, Vietnam. Sci. Total Environ. 2018, 631, 469-475. [CrossRef] [PubMed]

17. Du, P.; Thai, P.K.; Bai, Y.; Zhou, Z.; Xu, Z.; Zhang, X.; Wang, J.; Zhang, C.; Hao, F.; Li, X. Monitoring consumption of methadone and heroin in major Chinese cities by wastewater-based epidemiology. Drug Alcohol Depend. 2019, 205, 107532. [CrossRef] [PubMed]

18. Fallati, L.; Castiglioni, S.; Galli, P.; Riva, F.; Gracia-Lor, E.; Gonzalez-Marino, I.; Rousis, N.I.; Shifah, M.; Messa, M.C.; Strepparava, M.G.; et al. Use of legal and illegal substances in Male (Republic of Maldives) assessed by wastewater analysis. Sci. Total Environ. 2020, 698, 134207. [CrossRef] [PubMed]

19. Cyranoski, D. Chinese cities scan sewers for signs of illegal drug use. Nature 2018, 559, 310-311. [CrossRef] [PubMed]

20. Li, X.; Du, P.; Zhang, W.; Zhang, L. Wastewater: A new resource for the war against illicit drugs. Curr. Opin. Environ. Sci. Health 2019, 9, 73-76. [CrossRef]

21. Archer, E.; Castrignano, E.; Kasprzyk-Hordern, B.; Wolfaardt, G.M. Wastewater-based epidemiology and enantiomeric profiling for drugs of abuse in South African wastewaters. Sci. Total Environ. 2018, 625, 792-800. [CrossRef]

22. Causanilles, A.; Ruepert, C.; Ibanez, M.; Emke, E.; Hernandez, F.; de Voogt, P. Occurrence and fate of illicit drugs and pharmaceuticals in wastewater from two wastewater treatment plants in Costa Rica. Sci. Total Environ. 2017, 599, 98-107. [CrossRef]

23. Subedi, B.; Balakrishna, K.; Sinha, R.K.; Yamashita, N.; Balasubramanian, V.G.; Kannan, K. Mass loading and removal of pharmaceuticals and personal care products, including psychoactive and illicit drugs and artificial sweeteners, in five sewage treatment plants in India. J. Environ. Chem. Eng. 2015, 3, 2882-2891. [CrossRef]

24. Kanato, M.; Choomwattana, C.; Sarasiri, R.; Leyatikul, P. (Eds.) ASEAN Drug Monitoring Report 2017; ASEAN Narcotics Cooperation Center: Bangkok, Thailand, 2018.

25. Hall, W.; Prichard, J.; Kirkbride, P.; Bruno, R.; Thai, P.K.; Gartner, C.; Lai, F.Y.; Ort, C.; Mueller, J.F. An analysis of ethical issues in using wastewater analysis to monitor illicit drug use. Addiction 2012, 107, 1767-1773. [CrossRef]

26. Pardo, B.; Kilmer, B.; Huang, W. Contemporary Asian Drug Policy: Insights and Opportunities for Change; RAND Corporation: Santa Monica, CA, USA, 2019.

27. Li, K.; Du, P.; Xu, Z.; Gao, T.; Li, X. Occurrence of illicit drugs in surface waters in China. Environ. Pollut. 2016, 213, 395-402. [CrossRef] [PubMed]

28. Gao, T.; Du, P.; Xu, Z.; Li, X. Occurrence of new psychoactive substances in wastewater of major Chinese cities. Sci. Total Environ. 2017, 575, 963-969. [CrossRef] [PubMed]

29. Du, P.; Zhou, Z.; Huang, H.; Han, S.; Xu, Z.; Bai, Y.; Li, X. Estimating population exposure to phthalate esters in major Chinese cities through wastewater-based epidemiology. Sci. Total Environ. 2018, 643, 1602-1609. [CrossRef] [PubMed]

30. Li, J.; Hou, L.; Du, P.; Yang, J.; Li, K.; Xu, Z.; Wang, C.; Zhang, H.; Li, X. Estimation of amphetamine and methamphetamine uses in Beijing through sewage-based analysis. Sci. Total Environ. 2014, 490, 724-732. [CrossRef]

31. Du, P.; Zhou, Z.; Bai, Y.; Xu, Z.; Gao, T.; Fu, X.; Li, X. Estimating heroin abuse in major Chinese cities through wastewater-based epidemiology. Sci. Total Environ. 2017, 605, 158-165. [CrossRef]

32. Zuccato, E.; Chiabrando, C.; Castiglioni, S.; Bagnati, R.; Fanelli, R. Estimating community drug abuse by wastewater analysis. Environ. Health Perspect. 2008, 116, 1027-1032. [CrossRef]

33. Gao, J.; Xu, Z.; Li, X.; O’Brien, J.W.; Culshaw, P.N.; Thomas, K.V.; Tscharke, B.J.; Mueller, J.F.; Thai, P.K. Enantiomeric profiling of amphetamine and methamphetamine in wastewater: A 7-year study in regional and urban Queensland, Australia. Sci. Total Environ. 2018, 643, 827-834. [CrossRef]

34. Bijlsma, L.; Emke, E.; Hernandez, F.; de Voogt, P. Investigation of drugs of abuse and relevant metabolites in Dutch sewage water by liquid chromatography coupled to high resolution mass spectrometry. Chemosphere 2012, 89, 1399-1406. [CrossRef] 
35. EMCDDA (European Monitoring Centre for Drugs and Drug Addiction). Wastewater Analysis and Drugs-A European Multi-City Study; Publications Office of the European Union: Luxembourg, 2019.

36. Chiaia, A.C.; Banta-Green, C.; Field, J. Eliminating solid phase extraction with large-volume injection LC/MS/MS: Analysis of illicit and legal drugs and human urine indicators in US wastewaters. Environ. Sci. Technol. 2008, 42, 8841-8848. [CrossRef]

37. Du, P.; Li, K.; Li, J.; Xu, Z.; Fu, X.; Yang, J.; Zhang, H.; Li, X. Methamphetamine and ketamine use in major Chinese cities, a nationwide reconnaissance through sewage-based epidemiology. Water Res. 2015, 84, 76-84. [CrossRef]

38. Foppe, K.S.; Hammond-Weinberger, D.R.; Subedi, B. Estimation of the consumption of illicit drugs during special events in two communities in Western Kentucky, USA using sewage epidemiology. Sci. Total Environ. 2018, 633, 249-256. [CrossRef]

39. Huerta-Fontela, M.; Galceran, M.T.; Martin-Alonso, J.; Ventura, F. Occurrence of psychoactive stimulatory drugs in wastewaters in north-eastern Spain. Sci. Total Environ. 2008, 397, 31-40. [CrossRef] [PubMed]

40. Kim, K.Y.; Lai, F.Y.; Kim, H.Y.; Thai, P.K.; Mueller, J.F.; Oh, J.E. The first application of wastewater-based drug epidemiology in five South Korean cities. Sci. Total Environ. 2015, 524, 440-446. [CrossRef]

41. Lai, F.Y; Bruno, R.; Leung, H.W.; Thai, P.K.; Ort, C.; Carter, S.; Thompson, K.; Lam, P.K.; Mueller, J.F. Estimating daily and diurnal variations of illicit drug use in Hong Kong: A pilot study of using wastewater analysis in an Asian metropolitan city. Forensic Sci. Int. 2013, 233, 126-132. [CrossRef] [PubMed]

42. Li, X.; Du, P.; Zhang, W. Application of Wastewater-Based Epidemiology in China-From Wastewater Monitoring to Drug Control Efforts. In Wastewater-Based Epidemiology: Estimation of Community Consumption of Drugs and Diets; Subedi, B., Burgard, D.A., Loganathan, B.G., Eds.; American Chemical Society: Washington, DC, USA, 2019.

43. Metcalfe, C.; Tindale, K.; Li, H.; Rodayan, A.; Yargeau, V. Illicit drugs in Canadian municipal wastewater and estimates of community drug use. Environ. Pollut. 2010, 158, 3179-3185. [CrossRef]

44. SCORE (Sewage Analysis CORe Group Europe). Wastewater Monitoring Data 2011-2018 Sewage Analysis CORe Group Europe; Sewage Analysis CORe Group Europe: Lisbon, Portugal, 2019.

45. Skees, A.J.; Foppe, K.S.; Loganathan, B.; Subedi, B. Contamination profiles, mass loadings, and sewage epidemiology of neuropsychiatric and illicit drugs in wastewater and river waters from a community in the Midwestern United States. Sci. Total Environ. 2018, 631, 1457-1464. [CrossRef] [PubMed]

46. Van Nuijs, A.L.; Gheorghe, A.; Jorens, P.G.; Maudens, K.; Neels, H.; Covaci, A. Optimization, validation, and the application of liquid chromatography-tandem mass spectrometry for the analysis of new drugs of abuse in wastewater. Drug Test Anal. 2014, 6, 861-867. [CrossRef]

47. Castiglioni, S.; Zuccato, E.; Fanelli, R. Illicit Drugs in the Environment: Occurrence, Analysis, and Fate Using Mass Spectrometry; John Wiley \& Sons, Inc.: Hoboken, NJ, USA, 2011.

48. UNODC (United Nations Office on Drugs and Crime). The Challenge of Synthetic Drugs in East and South-East Asia, Trends and Patterns of Amphetamine-Type Stimulants and New Psychoactive Substances; United Nations Office on Drugs and Crime: Vienna, Austria, 2017.

49. EMCDDA (European Monitoring Centre for Drugs and Drug Addiction). Assessing Illicit Drugs in Wastewater: Advances in Wastewater-Based Drug Epidemiology; Publications Office of the European Union: Luxembourg, 2016.

50. Van Nuijs, A.L.N.; Mougel, J.F.; Tarcomnicu, I.; Bervoets, L.; Blust, R.; Jorens, P.G.; Neels, H.; Covica, A. A one year investigation of the occurrence of illicit drugs in wastewater from Brussels, Belgium. J. Environ. Monit. 2011, 13, 1008-1016. [CrossRef]

51. Castiglioni, S.; Bijlsma, L.; Covaci, A.; Emke, E.; Hernández, F.; Reid, M.; Ort, C.; Thomas, K.V.; van Nuijs, A.L.N.; de Voogt, P.; et al. Evaluation of uncertainties associated with the determination of community drug use through the measurement of sewage drug biomarkers. Environ. Sci. Technol. 2013, 47, 1452-1460. [CrossRef]

(C) 2020 by the authors. Licensee MDPI, Basel, Switzerland. This article is an open access article distributed under the terms and conditions of the Creative Commons Attribution (CC BY) license (http://creativecommons.org/licenses/by/4.0/). 